Matías Tueros $\cdot$ Eduardo A. Castro

Andrey A. Toropov

\title{
Maximum topological distance-based indices as molecular descriptors for QSPR. 3 - Calculation of the hydrophobicity of polyaromatic hydrocarbons
}

Received: 14 September 1999 / Accepted: 28 March 2001 / Published online: 21 June 2001

(C) Springer-Verlag 2001

\begin{abstract}
Maximum topological distance-based indices are used together with standard ones to compute the hydrophobicity of polyaromatic hydrocarbons. Several variables and higher-order regression equations are computed and shown to be excellent predictors for the chosen physical-chemistry property. This new alternative offers advantages the usual manner of deriving global topological indices for QSPR. Some possible future extensions are pointed out.
\end{abstract}

Keywords Detour matrix · Hydrophobicity · Topological indices · Polyaromatic hydrocarbons · QSAR/QSPR theory

\section{Introduction}

The topological geometry of molecules should pertain to either the weak polar-polar interactions or the geometric requirements for substrate-receptor complex formation in which the whole molecule takes part. The first sort of interactions, however, are relevant to such primary effects as substrate partitioning between phases of different polarity, soil sorption, association coefficients, etc. These primary effects and/or geometric demands for fitting into a receptor cavity (thus facilitating either hydrophobic or electronic interactions) can determine secondary biological effects such as acute toxicity, carcinogenecity, etc. [1]

Electronic supplementary material to this paper can be obtained by using the Springer Link server located at http://dx.doi.org/ $10.1007 / \mathrm{s} 008949010029$

M. Tueros · E.A. Castro $(\square)$

CEQUINOR, Departamento de Química,

Facultad de Ciencias Exactas, Universidad Nacional de La Plata, C.C. 962, La Plata 1900, Argentina

e-mail: castro@dalton.quimica.unlp.edu.ar

A.A. Toropov

Vostok Innovation Company, S. Azim street 4,

Tashkent 700047, Uzbekistan
Hydrophobic solutes [2] (also known as "structuremaking" solutes) are sparingly soluble in water, since the intermolecular forces between water and solute molecules are weaker than the hydrogen-bond interactions between the water molecules. [3, 4] The IR spectra of their solutions resemble that of water at higher temperatures and hence indicate a corresponding structural rearrangement as "structure makers". The dissolution of such molecules causes a positive change (loss) in entropy. The solute molecules or ions are placed in holes in the water structure, which are adaptable to the need of the solute molecule for free rotation. [5]

It is also worth mentioning that hydrophobic bonds play a key role in association and in conformational changes in biological systems, for example in stabilizing the helical structure by incorporation between two neighboring residues of the $\alpha$-helix. The helical form of DNA is stabilized by the addition of electrolytes, [6] and the effects are greatly influenced by the concentration.

On the other hand, the stereospecificity of the reduction of acetaldehyde by DPNH and ADH, leading to the formation of only one enantiomer of ethanol-1-D when a deuterium atom is transferred, is explicable in terms of a "hydrophobic region" at the active site that can distinguish the small alkyl group (hydrogen) from the large alkyl group (ethyl). [7] Good experimental evidence for a hydrophobic region in the active site is given by the discovery that long-chain fatty acid amides complex with DPNH and ADH. [8]

It is well known that tertiary structure of the protein arises from a tendency for many long chains to fold back on themselves with stabilization arising from interhelical hydrogen bonds, disulfide linkages, hydrophobic bonds, and ionic interactions. [9, 10, 11, 12] "Hydrophobic bond" is a loose term useful for describing the juxtaposition of nonpolar portions of the protein molecule produced by removing these nonpolar portions from the structure-forming water regions. [13] From a macroscopical point of view and from thermodynamic studies it would seem that the stability of these hydrophobic bonds is primarily due to a favorable entropy effect. [14] If it 
were to occur, the direct interaction of a nonpolar group would cause the formation of a highly ordered frozen array of water molecules around the nonpolar groups. [15]

Thus, several significant biological phenomena such as protein folding, membrane formation, drug binding to proteins, and the formation of amyloid plaques in Alzheimer's disease tissues are largely driven by hydrophobic interactions. In an extremely simplified view, water squeezes out nonpolar molecules or groups, resulting in attractive interactions between hydrophobic solutes. [16] From this simple and na picture, one can expect there could be a close relationship with the usual topological indices employed in QSAR/QSPR theory and primary and secondary reactivity effects.

Hydrophobic effects have been studied with numerous theoretical models and computer simulations. [17]

The hydrophobicity ( $\log \mathrm{P}$, octanol-water) of different sets of molecules has been predicted from their topological indices very effectively. $[18,19]$ Global topological indices were also found to correlate with biological data. In general, structure-activity/property models include parameters responsible for both main steps of the biological process: the penetration and the stereoelectronic interaction. In these cases the topological indices can be included in the models because of their relationship either with the penetration parameter (reflecting polarpolar interactions with the biological phases) or with the stereoelectronic one (representing substrate-receptor geometric correspondence). Some recent reviews on these issues that bring new ideas into focus in this area can be found in [20].

The aim of this paper is to present the results of several models to predict the hydrophobicity of polyaromatic hydrocarbons (i.e. polycyclic aromatic hydrocarbons). These models are based on maximum topological distance-based indices as molecular descriptors for QSPR/QSAR and they complement two previous studies on this issue [21, 22] about alkyl-benzenes and alcohols.

This paper in organized as follows: the next section deals with the explanation in detail of the particular choice of maximum topological distance-based indices making suitable comparisons with other similar ones. Then, we describe the calculation method and give the results, paying special attention to the analysis, in a comparative fashion, of the predicted results with alternative global topological descriptors. The degree of accuracy of the regression equations is discussed from the relevant statistical parameters as well as their predictive capabilities. Finally, we present the conclusions in order to show the advantages of the present choice of descriptors and pointing out some possible further extensions to study other physicalchemistry properties and biological activities.

\section{Maximum topological distance-based indices}

The term "topological index" was first proposed by Hosoya [23] for characterizing the topological nature of a graph. It is an integer quite easily obtained from a graph by a specified recipe. Since then, more than one hundred different topological indices for chemical graphs have been proposed. [24]

A graph is a mathematical object and can be represented either in a geometrical or algebraic way, i.e. via a matrix. Define a $\mathrm{N} \times \mathrm{N}$ adjacency matrix, A, for a graph, of the order $\mathrm{N}=\mathrm{V}$ (where $\mathrm{V}$ is the number of vertices), with elements such that $A_{i j}=\left\{1\right.$ for an adjacent pair $v_{i}$ and $\mathrm{v}_{\mathrm{j}}$, and 0 otherwise $\}$. If $\mathrm{G}$ is given, then $\mathrm{A}$ is uniquely determined, and vice versa. The distance matrix $\mathrm{D}$ can be defined for $G$ with elements $D_{i j}=d(i j)$, the distance, or the least number of steps from $\mathrm{v}_{\mathrm{i}}$ to $\mathrm{v}_{\mathrm{j}}$. If $\mathrm{a}$ graph $\mathrm{G}$ is given, the matrix $\mathrm{D}$ can be reproduced uniquely, while by wiping out all the elements in D except for unity, one obtains A. Thus one can assert that matrices $\mathrm{A}$ and $\mathrm{D}$, for $\mathrm{G}$ are mathematically equivalent

$$
\begin{aligned}
& \begin{array}{lllll}
1 & 2 & 3 & 4 & 5
\end{array} \\
& G \quad o-o-o-o-o \\
& A=\left[\begin{array}{lllll}
0 & 1 & 0 & 0 & 0 \\
1 & 0 & 1 & 0 & 0 \\
0 & 1 & 0 & 1 & 0 \\
0 & 0 & 1 & 0 & 1 \\
0 & 0 & 0 & 1 & 0
\end{array}\right] \quad D=\left[\begin{array}{lllll}
0 & 1 & 2 & 3 & 4 \\
1 & 0 & 1 & 2 & 3 \\
2 & 1 & 0 & 1 & 2 \\
3 & 2 & 1 & 0 & 1 \\
4 & 3 & 2 & 1 & 0
\end{array}\right] \\
& A \leftrightarrow G \leftrightarrow D
\end{aligned}
$$

Distance matrix D has been particularly useful and fruitful for defining several distance-based indices as molecular descriptors for QSPR/QSAR. [1] Later on, an interesting change was suggested in the definition of $\mathrm{D}$; to resort to the concept of non-redundant maximum distance instead of least steps from $v_{i}$ to $v_{j}$. $[25,26]$ This new $D_{\max }$ matrix (detour matrix) opened the possibility of redefining all indices associated with the distance concept and gave rise to a new set of "maximum topological distance-based indices". Several initial numerical tests on the basis of these new indices have proven to be quite promising since in many cases they yield better results than those developed from the standard definition of distance. [21, 22, 25, 26]

Here our purpose is to extend the set of chemical properties and biological activities to be tested in order to obtain more definitive conclusions about the usefulness of this new set of topological indices. Thus, we have chosen the hydrophobicity of a group of 44 polyaromatic hydrocarbons and have selected several wellknown indices based upon the topological distance matrix to compute the corresponding regression equations. These indices are the Wiener index (W), the Harary index $(\mathrm{H})$, the Balaban index $(\mathrm{J})$, the molecular topological index of Schultz (MTI), zero-, first-, and second-order molecular connectivity indices $\left({ }^{0} \chi,{ }^{1} \chi\right.$, and ${ }^{2} \chi$, respectively), and Zagreb group indices $\left(\mathrm{M}_{1}\right.$ and $\left.\mathrm{M}_{2}\right)$.

Since all these are well-known global topological indices and their definitions have been published elsewhere, $[1,21,22,25,26]$ we do not include their formulae here. 


\section{Calculation method}

We have selected the set of 44 polyaromatic hydrocarbons chosen by Basak et al. [18] and made a thorough search of the best one-, two-, three-, four-, and five-variable correlations up to third-order equations for hydrophobicity. Although the number of compounds chosen (44) is rather small, numerical results do not change significantly with a larger set. The fitting equations have the general form

$$
\begin{aligned}
P= & \sum_{i=1}^{m} a_{i} q_{i}+b \\
P= & \sum_{i=1}^{m} a_{i} q^{i} p^{i}+b_{i} q^{i}+c_{i} p^{i}+d \\
P= & \sum_{i=1}^{m} a_{i} q^{i} p^{i}+b_{i} q^{i}+c_{i} p^{i}+d_{i} q^{i}+e_{i} r^{i}+f_{i} p^{i}+g \\
P= & \sum_{i=1}^{m} a_{i} q^{i} p^{i}+b_{i} q^{i} r^{i}+c_{i} p^{i} r^{i}+d_{i} q^{i} s^{i}+e_{i} p^{i} s^{i} \\
& +f_{i} r^{i} s^{i}+g_{i} q^{i}+h_{i} p^{i}+j_{i} s^{i}+k \\
P= & \sum_{i=1}^{m} a_{i} q^{i} p^{i}+b_{i} q^{i} r^{i}+c_{i} p^{i} r^{i}+d_{i} q^{i} s^{i}+e_{i} p^{i} t^{i}+f_{i} p^{i} t^{i} \\
& +g_{i} r^{i} t^{i}+h_{i} s^{i} t^{i}+j_{i} p^{i} s^{i}+k_{i} r^{i} s^{i}+l_{i} p^{i} \\
& +m_{i} q^{i}+n_{i} r^{i}+o_{i} s^{i}+u_{i} t^{i}+v
\end{aligned}
$$

where $m=1,2,3 ; a_{i}, b_{i}, c_{i}, d_{i}, e_{i}, f_{i}, g_{i}, h_{i}, j_{i}, k_{i}, l_{i}, m_{i}, n_{i}$, $\mathrm{o}_{\mathrm{i}}, \mathrm{u}_{\mathrm{i}}, \mathrm{b}, \mathrm{d}, \mathrm{g}, \mathrm{k}$, and $\mathrm{v}$ are real numbers arising from the fitting procedure, $\mathrm{P}$ is the property (i.e. hydrophobicity) and $\mathrm{p}, \mathrm{q}, \mathrm{r}, \mathrm{s}$, and $\mathrm{t}$ are the topological descriptors (i.e. ${ }^{0} \chi$, ${ }^{1} \chi,{ }^{2} \chi, \mathrm{M}_{1}, \mathrm{M}_{2}, \mathrm{~W}, \mathrm{H}, \mathrm{J}, \mathrm{MTI}, \mathrm{W}_{\max }, \mathrm{H}_{\max }, \mathrm{J}_{\max }$, and $\left.\mathrm{MTI}_{\max }\right)$. No pair of these variables is not closely correlated, so they can be used as (nearly) independent variables in the polynomial regression equations.

We have previously verified the need to resort to several variables and higher-order equations to attain meaningful predictive models within the realm of QSAR/QSPR and that it is not necessary to go beyond third-order equations. [27, 28, 29, 30]

We have employed the standard software included in the MATHEMATICA package [31] to perform the multilinear regression analysis of hydrophobicity versus global topological indices. The whole set of descriptors was used in two steps: first we made a complete search among the standard indices based on the normal definition of $\mathrm{D}$, and then we performed a total search among the whole set of the topological indices. This particular partition was selected just for comparative purposes.

\section{Results}

In Table 1 we display the topological descriptors for the molecular set. The first choice consisted of the usual indices while the second choice added to the first set those computed on the basis of the maximum distance matrix.
Observed vs. Predicted Values

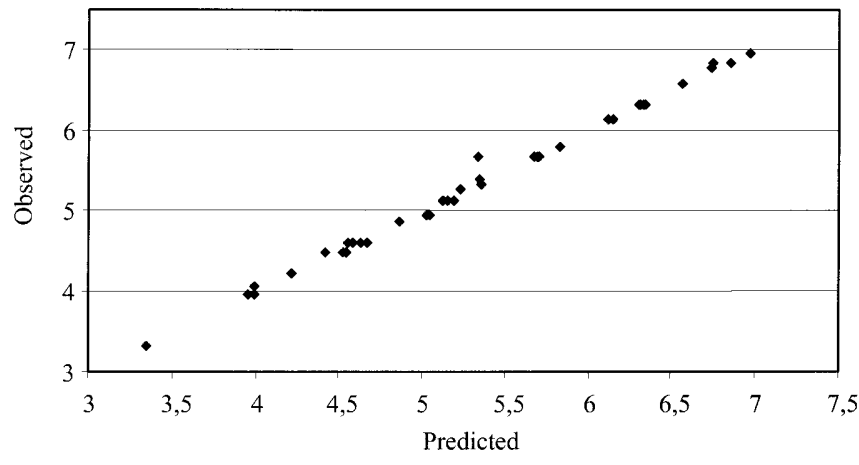

Fig. 1 Observed versus predicted hydrophobicity of polyaromatic hydrocarbons via the best one-variable linear regression (i.e. hydrophobicity $=\mathrm{a}^{0} \chi+\mathrm{b}$ where $\mathrm{a}, \mathrm{b} \subset \Re$ )

Observed vs. Predicted Values

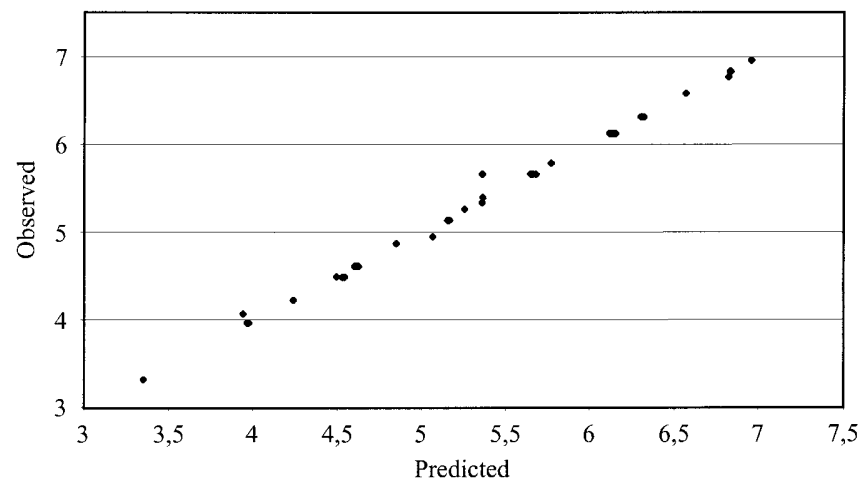

Fig. 2 Observed versus predicted hydrophobicity of polyaromatic hydrocarbons via the best one-variable second-order regression (i.e hydrophobicity $=\mathrm{A}^{0} \chi+\mathrm{B}\left({ }^{0} \chi\right)^{2}+\mathrm{C}$ where $\mathrm{A}, \mathrm{B}, \mathrm{C} \subset \Re$ )

For the first choice of descriptors, the best one-, two-,..., five-variable correlations are (shown in Tables 2 and 3): ${ }^{0} \chi,{ }^{1} \chi,{ }^{2} \chi, M_{1}, M_{2}$, W, H, J, MTI.

Similar results hold for third-order equations.

The best one-, two-,..., five-variable correlations among the complete set of topological indices are shown in Tables 4 and 5): ${ }^{0} \chi,{ }^{1} \chi,{ }^{2} \chi, \mathrm{M}_{1}, \mathrm{M}_{2}, \mathrm{~W}, \mathrm{H}, \mathrm{J}$. MTI, $\mathrm{W}_{\max }, \mathrm{H}_{\max }, \mathrm{J}_{\max }, \mathrm{MTI}_{\max }$.

Once again, similar results hold for third-order equations, so that we do not include them here. Complete results are available as supplementary material.

A comparison of the results for the first restricted molecular descriptors set (i.e. ${ }^{0} \chi,{ }^{1} \chi,{ }^{2} \chi, \mathrm{M}_{1}, \mathrm{M}_{2}, \mathrm{~W}, \mathrm{H}, \mathrm{J}$, and MTI) with those derived from the second more complete molecular descriptors set (i.e. ${ }^{0} \chi,{ }^{1} \chi,{ }^{2} \chi, \mathrm{M}_{1}, \mathrm{M}_{2}$, $\mathrm{W}, \mathrm{H}, \mathrm{J}, \mathrm{MTI}, \mathrm{W}_{\max }, \mathrm{H}_{\max }, \mathrm{J}_{\max }$, and $\mathrm{MTI}_{\max }$ ) clearly shows that those descriptors based on the detour matrix perform better.

In Figs. 1 and 2 we show two relationships (best one-variable linear regression and best one-variable second-order regression, respectively) between theoretical and experimental hydrophobicity data for polyaromatic 
Table 1 Experimental hydrophobicity and topological indices of polyaromatic hydrocarbons

\begin{tabular}{|c|c|c|c|c|c|c|c|c|c|c|c|c|c|c|}
\hline Molecule & Hydr & ${ }^{0} \chi$ & ${ }^{1} \chi$ & ${ }^{2} \chi$ & M1 & M2 & W & $\mathrm{H}$ & $\mathrm{J}$ & MTI & $\mathrm{W}_{\max }$ & $\mathrm{H}_{\max }$ & $\mathrm{J}_{\max }$ & $\mathrm{MTI}_{\max }$ \\
\hline ethyl & 4 & 39 & 830 & 615 & 0 & 140 & 182 & 33 & 37 & 16 & 518 & .444 & 662 & 280 \\
\hline nthracene & & 12 & 653 & 17 & 108 & 264 & 632 & & & 2952 & 2542 & & & \\
\hline lchrysene & & & & & 114 & & & & & & & & & \\
\hline thylchrysene & 313 & 12.820 & 18.653 & 17.066 & 108 & 264 & 644 & 65.479 & 1.518 & 3002 & 2550 & 520 & 0.363 & \\
\hline ethylbenzo[e]pyrene & 773 & 13.974 & 20.653 & 19.399 & 126 & 318 & 748 & .985 & 1.551 & 3567 & 3532 & 3.480 & 0.312 & 16851 \\
\hline 10-dimethylanthracene & 5.788 & 11.121 & 15.575 & 13.885 & 88 & 216 & 378 & 0.952 & 1.831 & 1724 & 1342 & 2.665 & 0.488 & 6076 \\
\hline methylanthracene & 5.139 & 10.251 & 14.720 & 13.023 & 82 & 198 & 326 & 45.769 & 1.760 & 1515 & 1174 & 10.447 & 0.465 & 5367 \\
\hline cenaphthene & .070 & 7.966 & 11.899 & 10.593 & 68 & 166 & 166 & 33.400 & 1.845 & 824 & 627 & 7.043 & 0.474 & 2970 \\
\hline & 490 & .380 & 13.865 & 12.161 & 76 & 180 & 279 & 40.786 & 1.682 & 1324 & 1015 & 8.339 & 0.444 & 4692 \\
\hline Benzo[a]fluorene & 5.339 & 11.242 & 16.865 & 15.115 & 98 & 242 & 461 & 56.057 & 1.560 & 2211 & 1914 & 9.821 & 0.357 & 9060 \\
\hline enzo[a]pyrene & 6.124 & 13.104 & 19.832 & 18.257 & 120 & 302 & 680 & 680 & & 3302 & 3166 & 11.523 & 0.305 & 15242 \\
\hline nthene & & 13.104 & 19.865 & 112 & 120 & 304 & 676 & 73.668 & & 3271 & 3201 & .414 & 02 & 15406 \\
\hline b] & & 12 & 32 & & 98 & 2 & 471 & 8 & & 62 & 6 & 65 & & 28 \\
\hline Benz & & 1 & 5 & & 120 & & 6 & & & 0 & & & & \\
\hline ne & 4 & 1 & 2 & 20 & 138 & 356 & 815 & 43 & 5 & 4032 & 3 & 93 & 59 & 32 \\
\hline j]fluoranthene & 24 & 104 & 5 & 08 & 120 & 304 & 678 & 11 & 0 & 3282 & 8 & 89 & 03 & 38 \\
\hline $\mathrm{Cn}$ & 64 & 949 & 65 & 98 & 102 & 250 & 545 & 21 & 8 & 2584 & 2275 & 60 & 51 & 64 \\
\hline Dibenz $[\mathrm{a}, \mathrm{h}] \mathrm{a}$ & 838 & 14.518 & 21.798 & 19.782 & 128 & 316 & 971 & 742 & 1.346 & 4620 & 4261 & 12.724 & 0.292 & 20192 \\
\hline Didenz $[\mathrm{a}, \mathrm{j}] \mathrm{ant}$ & 838 & 14.518 & 21.798 & 19.782 & 128 & 316 & 955 & 974 & 67 & 4540 & 4265 & 12.712 & 92 & 20208 \\
\hline FIu & 0 & 10.535 & 399 & 14.278 & 94 & 236 & 364 & 67 & & 1772 & 1 & & 0.368 & 56 \\
\hline Flu & & 673 & 12.899 & 305 & 72 & 174 & 219 & 83 & & 1056 & 315 & 03 & 52 & 3812 \\
\hline lene & & 812 & 933 & 78 & 50 & 114 & 109 & 00 & & 520 & 45 & 98 & & 560 \\
\hline rene & & 380 & 399 & & 76 & 182 & 271 & & & 1284 & 19 & 94 & & 08 \\
\hline & & 10 & & & 94 & & 2 & & & 70 & & 93 & 3 & 74 \\
\hline Triphe & 4 & 11 & 9 & 15 & 102 & 252 & 5 & 29 & & 2424 & 9 & 49 & 59 & 10 \\
\hline $2-n$ & 965 & 682 & 720 & 9.446 & 56 & 128 & 144 & 33 & 2 & 664 & 424 & 49 & 29 & 390 \\
\hline ene & 313 & 12.820 & 687 & 16.853 & 108 & 266 & 620 & 63 & 73 & 2898 & 2538 & 93 & 65 & 11798 \\
\hline thylnaphthaler & 4.614 & 552 & 575 & 10.288 & 62 & 146 & 17 & 00 & 2. & 790 & 516 & .161 & 64 & 2270 \\
\hline Pery & 6.124 & 104 & 865 & 18.108 & 120 & 304 & 65 & 90 & 5 & 3172 & 146 & 42 & 08 & 16 \\
\hline enz & 6.124 & 13.104 & 19.832 & 18.261 & 120 & 302 & 69 & 31 & 1. & 3384 & 3178 & 27 & 04 & 96 \\
\hline Benz [ & 5.664 & 11.949 & 17.832 & 15.971 & 102 & 24 & 553 & 363 & 1.5 & 2624 & 2265 & 10.509 & 52 & 10624 \\
\hline & 5.664 & 242 & 365 & 35 & 98 & 242 & 440 & & & 14 & & 10 & & 8956 \\
\hline & 13 & 820 & 87 & 353 & 108 & 266 & 632 & & & 2948 & 60 & 482 & 62 & 11892 \\
\hline & & 57 & & & 112 & 276 & 714 & & & 88 & & & 76 & 68 \\
\hline & 3 & 20 & & 33 & 108 & 266 & 624 & & & 16 & & & 64 & \\
\hline & & 51 & 87 & 13.256 & 82 & 19 & 334 & 54 & & 1547 & 0 & 59 & 63 & 93 \\
\hline & 139 & 10.251 & 653 & 13.429 & 82 & 19 & 342 & 96 & & 1587 & 11 & 19 & 0.465 & 5369 \\
\hline & 4.614 & 552 & 508 & 10.713 & 62 & 142 & 186 & 150 & & 834 & 512 & 10.211 & 0.669 & 2254 \\
\hline thalene & 4 & 52 & 42 & 10. & 62 & 1 & 18 & 00 & 1. & 818 & 514 & 10.191 & 67 & 2262 \\
\hline $1-m$ & 4874 & 9.544 & 13.720 & 12.360 & 78 & 190 & 267 & 41.467 & 1.786 & 1255 & 959 & 9.617 & 71 & 4429 \\
\hline $1-m$ & 3965 & 7.682 & 10.754 & 9233 & 56 & 130 & 140 & 27.850 & 1.993 & 646 & 426 & 8.024 & 0.626 & 1898 \\
\hline halene & 4.614 & 8.552 & 11.575 & 10.288 & 62 & 146 & 176 & 32.000 & 2.053 & 790 & 518 & 10.141 & 0.662 & 2278 \\
\hline & & 552 & 542 & 10.525 & 62 & 144 & 179 & 31.833 & 2.015 & 804 & 515 & 10.175 & 0.665 & 2266 \\
\hline 1,4,5-trimethylnaphthalene & 5.263 & 9.422 & 12.397 & 11.363 & 68 & 162 & 216 & 36.400 & 2.123 & 948 & 618 & 12.378 & 0.699 & 2688 \\
\hline
\end{tabular}

Table 2 Best linear one-, two-,...., five-variable correlations

\begin{tabular}{llll}
\hline Variables & $\begin{array}{l}\text { Regression } \\
\text { coefficient }\end{array}$ & Final loss & $\begin{array}{l}\text { Variance } \\
\text { Explained }\end{array}$ \\
\hline${ }^{0} \chi$ & 0.9749 & 1.8688 & $95.04 \%$ \\
${ }^{0} \chi,{ }^{1} \chi$ & 0.9964 & 0.2687 & $99.29 \%$ \\
${ }^{0} \chi,{ }^{1} \chi,{ }_{\mathrm{J}}$ & 0.9966 & 0.2534 & $99.66 \%$ \\
${ }^{0} \chi,{ }^{1} \chi,{ }^{2} \chi, \mathrm{M}_{1}$ & 0.9970 & 0.2269 & $99.70 \%$ \\
${ }^{0} \chi,{ }^{1} \chi,{ }^{2} \chi, \mathrm{M}_{1}, \mathrm{M}_{2}$ & 0.9972 & 0.2078 & $99.72 \%$ \\
\hline
\end{tabular}

hydrocarbons. Complete results (i.e. best one-variable third-order, best two-variables first-order, etc. regressions) are available as supplementary material.

The analysis of above results reveals the excellent predictive power of the present regression for computing hydrophobicity. A comparative examination of previous equations allows us to verify the better performance of
Table 3 Best quadratic one-, two-,..., five-variable correlations

\begin{tabular}{llll}
\hline Variables & $\begin{array}{l}\text { Regression } \\
\text { coefficient }\end{array}$ & Final loss & $\begin{array}{l}\text { Variance } \\
\text { explained }\end{array}$ \\
\hline${ }^{0} \chi$ & 0.9751 & 1.4452 & $96.43 \%$ \\
${ }^{0} \chi,{ }^{1} \chi$ & 0.9966 & 0.2588 & $99.31 \%$ \\
${ }^{0} \chi,{ }^{1} \chi, \mathrm{J}$ & 0.9972 & 0.2140 & $99.43 \%$ \\
${ }^{0} \chi,{ }^{1} \chi,{ }^{2} \chi, \mathrm{M}_{1}$ & 0.9973 & 0.2032 & $99.46 \%$ \\
${ }^{0} \chi,{ }^{1} \chi,{ }^{2} \chi, \mathrm{M}_{1}, \mathrm{M}_{2}$ & 0.9977 & 0.1767 & $99.53 \%$ \\
\hline
\end{tabular}

topological indices based on maximum distance matrix with respect to the others. In this regard, especially important are Balaban and Harary maximum indices. We can also see that higher-order equations improve on linear ones, although the differences are not spectacular. A similar comment applies on going from one- to severalvariable equations. 
Table 4 Best linear one-, two-,..., five-variable correlations

\begin{tabular}{llll}
\hline Variables & $\begin{array}{l}\text { Regression } \\
\text { coefficient }\end{array}$ & Final loss & $\begin{array}{l}\text { Variance } \\
\text { explained }\end{array}$ \\
\hline${ }^{0} \chi$ & 0.9749 & 1.8688 & $95.04 \%$ \\
${ }^{0} \chi, \mathrm{H}_{\max }$ & 0.9972 & 0.2143 & $99.43 \%$ \\
${ }^{0} \chi,{ }^{1} \chi, \mathrm{H}_{\max }$ & 0.9976 & 0.1833 & $99.51 \%$ \\
${ }^{0} \chi,{ }^{1} \chi, \mathrm{H}_{\max }, \mathrm{J}_{\max }$ & 0.9977 & 0.1706 & $99.55 \%$ \\
${ }^{0} \chi,{ }^{1} \chi, \mathrm{MTI}, \mathrm{H}_{\max }, \mathrm{J}_{\max }$ & 0.9978 & 0.1684 & $99.55 \%$ \\
\hline
\end{tabular}

Table 5 Best quadratic one-, two-,..., five-variable correlations

\begin{tabular}{llll}
\hline Variables & $\begin{array}{l}\text { Correlation } \\
\text { coefficient }\end{array}$ & Final loss & $\begin{array}{l}\text { Variance } \\
\text { explained }\end{array}$ \\
\hline${ }^{0} \chi$ & 0.9751 & 1.4452 & $96.43 \%$ \\
${ }^{0} \chi, \mathrm{H}_{\max }$ & 0.9972 & 0.2112 & $99.44 \%$ \\
${ }^{0} \chi,{ }^{0} \chi, \mathrm{H}_{\max }$ & 0.9977 & 0.1711 & $99.55 \%$ \\
${ }^{0} \chi,{ }^{1} \chi, \mathrm{H}_{\max }, \mathrm{J}_{\max }$ & 0.9979 & 0.1612 & $99.57 \%$ \\
${ }^{0} \chi,{ }^{1} \chi, \mathrm{MTI}, \mathrm{H}_{\max }, \mathrm{J}_{\max }$ & 0.9980 & 0.1513 & $99.60 \%$ \\
\hline
\end{tabular}

\section{Conclusions}

The inclusion of maximum distance-based topological indices gives significant improvements in the calculations of regression equations for prediction the hydrophobicity of polyaromatic hydrocarbons compared to the standard descriptors derived from the usual distance matrix. It is especially important to resort to several variables and higher-order equations to attain very good predictive models. All these conclusions agree with those derived in previous studies on this issue.

Since we have up to now analyzed just two physicalchemistry properties (boiling points and hydrophobicity) for a very specialized set of molecules (hydrocarbons and alcohols), we consider there is not yet enough room to give definitive conclusions about the real merits of the proposed alternative set of maximum distance based indices as molecular descriptors for QSPR. However, the present results are sufficient to encourage new efforts to look for new application areas and different molecules in order to test these new topological descriptors.

Research along these lines is being carried out in our laboratories and results will be published elsewhere.

Supplementary material Complete results are available as supplementary material or upon request to the corresponding author.

Acknowledgements The authors thank two referees, whose comments helped significantly to improve the original version of the paper.

\section{References}

1. Mekenyan, O.; Basak, S. C. Topological indices and chemical reactivity. In Graph Theoretical Approaches to Chemical Reactivity; Bonchev, D; Mekenyan, O., Eds.; Kluwer: Dordrecht, 1994, p. 232.
2. Bene, J. D.; Pople, J. A. J. Chem. Phys. 1970, 52, 4858.

3. Luck, W. P. A. Top. Curr. Chem. 1976, 64, 115.

4. Luck, W. P. A. The hydrogen bond recent developments. In Theory and Experiment, Schuster P. et al., Eds.; NorthHolland: Amsterdam, 1976, Chapter 28.

5. Gutman, V. The Donor-Acceptor Approach to Molecular Interactions; Plenum Press: New York, 1978, p. 95.

6. Eagland, D. A comprehensive treatise. In Water, vol. 5, Franks F. Ed.; Plenum Press: New York, 1975, p. 1.

7. Kosower, E. M. Molecular Biochemistry; McGraw-Hill: New York, 1962, p. 218.

8. Winer, A. D.; Theorell, H. Acta Chem. Scand. 1960, 14, 1729 .

9. Lindestrom-Lang, K. V.; Schellman, J. A. The Enzymes, vol. 1; Academic Press: New York, 1959, chapter 10.

10. Boyer, P. D. Protein Structure and Function Brookhaven Symposia in Biology, 1960, 13, BNL 608 (C-30), p. 1.

11. Klotz, I. M. Protein Structure and Function Brookhaven Symposia in Biology, 1960, 13 BNL 608 (C-30), p. 25.

12. Scheraga, H. A. Protein Structure and Function Brookhaven Symposia in Biology, 1960, 13, BNL 608 (C-30), p. 71.

13. Kosower, E. M. Molecular Biochemistry; McGraw-Hill: New York, 1962, p. 275

14. Kauzmann, W. Adv. Protein Chem. 1959, 14, 1.

15. Salem, L. Intermolecular forces in biological systems. In Electronic Aspects of Biochemistry; Pullman B. Ed.; Academic Press: New York, 1967, p. 297.

16. Richards, F. M. Sci. Am. 1991, 264, 54.

17. (a) Oobatake, M.; Ooi, T. Prog. Biophys. Mol. Biol. 1993, 59 , 237. (b) Giesen, D. J.; Cramer, C. J.; Truhlar, D. G. J. Phys. Chem. 1994, 98, 4141. (c) Tuñón, I.; Silla, E.; Pascual-Ahuir, J. L J. Phys. Chem. 1994, 98, 377. (d) Fukunishi, Y.; Suzuki, M. J. Phys. Chem. 1996, 100, 5634. (e) Ashbaugh, H. S.; Kaler, E. W.; Paulaitis, M. E. Biophys. J. 1998, 75, 755. (f) Rank, J. A.; Baker, D. Protein Sci. 1997, 6, 347. (g) Besseling, N. A. M.; Lyklema, J. J. Phys. Chem. B 1997, 101, 7604. (h) Madan, B.; Sharp, K. J. Phys. Chem. B 1997, 101, 11237. (i) Matubayasi, N.; Reed, L. H.; Levy, R. M. J. Phys. Chem. 1994, 98, 10640. (j) Kinoshita, M.; Hirata, F. J. Chem. Phys. 1997, 106, 5202. (k) Hummer, G.; Garde, S. Phys. Rev. Lett. 1998, 80, 4193. (1) Wallqvist, A.; Berne, B. J. J. Phys. Chem. 1995, 99, 2893. (m) Head-Gordon, T, J. Am. Chem. Soc. 1995, 117, 501. (n) Garde, S.; Hummer, G.; Paulaitis. M. E. Faraday Discuss. 1996, 103, 125. (o) Lüdemann, S.; Abseher. R.; Schreiber, H.; Steinhauser, O. J. Am. Chem. Soc. 1997, 119, 4296. (p) Forsman, J.; Jönsson, J. J. Chem. Phys. 1994, 101, 5116. (q) Beutler, T. C.; Béguelin, D. R.; Van Gunsteren, W. F. J. Chem. Phys. 1995, 102, 3787. (r) Beglov, D.; Roux, B. J. Chem. Phys. 1994, 100, 9050. (s) Silverstein, K. A. T.; Haytmet, A. D. J.; Dill, K. A. J. Am. Chem. Soc. 1998, 120 3166. (t) Arthur, J. W.; Haymet, A. D. J. Chem. Phys. 1998, 109, 7991. (u) Cheng, Y. K.; Rossky, P. J. Nature 1998, 392, 696. (v) Lum, K.; Luzar, A. Phys. Rev. E 1997, 56, R6283. (w) Hummer, G.; Garde, S.; García, A. E.; Pohorille, A.; Pratt, L. R. Proc. Natl. Acad. Sci. USA 1996, 93, 8951. (x) Berne, B. J. Proc. Natl. Acad. Sci. USA 1996, 93, 8800. (y) Lum, K.; Chandler, D.; Weeks, J. D. J. Phys. Chem. B 1999, 103, 4570. (z) Hummer, G. J. Am. Chem. Soc. 1999, 121, 6299 .

18. (a) Basak, S. C.; Niemi, G. J.; Veith, G. D. J. Math. Chem. 1990, 4, 185. (b) Murray, W. J.; Hall, L. H.; Kier, L. B. J. Pharm. Sci. 1975, 64, 1978

19. Mekenyan, O.; Weith, G.; Bradburry, S.; Russom, C. Quant. Str-Act. Relat. 1993, 12.

20. Lipkowitz, K. B.; Boyd, D. B. (Eds.) Reviews in Computational Chemistry, vol. 11; Wiley-VCH: New York, 1997, chapters 3-5.

21. Firpo, M.; Gavernet, L.; Castro, E. A.; Toropov, A. A. J. Mol. Struct. (Theochem) 2000, 501, 419.

22. Tueros, M.; Castro, E. A.; Toropov, A. A. Comput. Chem. 2000, 24, 571.

23. Hosoya, H. Bull. Chem. Soc. Jpn. 1971, 44, 2332. 
24. Rouvray, D. The origins of chemical graph theory. In Chemical Graph Theory; Bonchev, D.; Rouvray, D. H. Eds.; Abacus Press/Gordon and Breach: New York, 1991.

25. (a) Toropov, A. A.; Toropova, A. P. Russ. J. Coord. Chem. 1997, 23, 789. (b) Toropov, A. A.; Toropova, A. P. Russ. J. Coord. Chem. 1998, 24, 89.

26. Harary, F. Graph Theory; Addison-Wesley: Reading, MA, 1969 , p. 203.
27. Romanelli. G.; Cafferata. L. F. R.; Castro, E. A. J. Mol. Struct. (Theochem) 2000, 504, 261.

28. Firpo, M.; Gavernet, L.; Castro, E. A. Rom. J. Phys. 1999, 44(1,2), 181.

29. Firpo, M.; Gavernet, L.; Castro, E. A. Polish J. Chem. 1999, $73,1041$.

30. Castro, E. A. Comput. Chem. 1997, 21, 305.

31. Adamchik, V. Guide to Standard Mathematica Package Version 222, Technical Report, Wolfram Research, 1999. 